\title{
EL CONCEPTO DE SOLIDARIDAD DESDE EL PENSAMIENTO FILOSÓFICO DEL DERECHO DE JESÚS GONZÁLEZ AMUCHASTEGUI
}

\section{THE CONCEPT OF SOLIDARITY FROM THE PHILOSOPHICAL THOUGHT OF THE LAW OF JESÚS GONZÁLEZ AMUCHASTEGUI}

\author{
Jainer Enrique García Gómez \\ Docente \\ Universidad del Cauca \\ jeglaw@live.com \\ Colombia, Cauca \\ Alejandra Galvís Triviño \\ Estudiante de Derecho \\ Universidad Cooperativa de Colombia \\ alejagalvis96@gmail.com \\ Colombia, Bogotá
}

\section{SUMARIO}

- Introducción.

- La fuente del concepto de solidaridad de Jesús González Amuchastegui.

- Del individualism posesivo al individualismo solidario de Jesús González Amuchastegui.

- El individualismo solidario o la solidaridad en el desarrollo de los Derechos Humanos.

- El concepto de solidaridad de Amuchastegui como justificante para las obligaciones de los individuos en los Derechos Humanos.

- Conclusiones.

\section{RESUMEN}

El siguiente trabajo de investigación pretende analizar la construcción del concepto de solidaridad desde la perspectiva del filósofo de derecho español, Jesús González Amuchastegui. Para alcanzarlo, la investigación utiliza el método hermenéutico, buscando el origen, fuente y elementos de la construcción del concepto en el autor. Un análisis y estudio de los argumentos y soportes utilizados por Amuchastegui para llegar a hablar de la solidaridad desde su visión como filósofo del Derecho. La construcción del concepto asumida por Amuchastegui fue tomada desde el Derecho y con elementos de Louis Blanc lo cual lo condujo a tener una integración de la dimensión social de los individuos para una conciliación entre los intereses particulares y los intereses colectivos, una armonía entre libertad, sociedad y fraternidad o solidaridad convirtiéndose en una oposición al prejuicio egoísta o al individualismo posesivo para lograr un desarrollo de la autonomía individual.

\begin{abstract}
The following research aims to determine, the construction of the concept of solidarity from a vision of the philosophy of law Jesús González Amuchastegui. To reach, the research uses the hermeneutic method, this looks for the origin, source and elements of the construction of the concept in the author. An analysis and study of the arguments and supports used by Amuchastegui to talk about solidarity in his vision as a philosopher of Law. The construction of the concept of Amuchastegui was taken from the Law and with elements of Louis Blanc, this integrated the social dimension of the individuals, a conciliation between the particular interests and the collective interests,
\end{abstract}


a harmony between freedom, society and fraternity or solidarity becoming an opposition to selfish prejudice or possessive individualism to achieve a development of individual autonomy.

\section{PALABRA CLAVE}

Autonomía individual; libertad; sociedad; solidaridad.

\section{KEYWORDS}

Freedom; individual autonomy; society; solidarity.

\section{INTRODUCCIÓN}

El individuo en el mundo actual se encuentra afectado por múltiples factores para el desarrollo de la vida autónoma como: el económico, cultural, migratorio, social, político, entre otros, aumentándose cada vez más en las realidades sociales y materializándose en la pérdida de la libertad. El valor y principio de la libertad y la igualdad que rigen los Estados actuales no tienen una capacidad efectiva para fundamentar y proteger de forma apropiada la vida autónoma, por eso y percibiendo la dificultad, Jesús González Amuchastegui, ya desaparecido, propuso hacer de la solidaridad parte de la sociedad y del derecho para alcanzar la efectivización del progreso individual y social. Este autor convoca al igual que Javier de Lucas (1993) da una mirada hacia el valor de la solidaridad como una necesidad de las sociedades actuales, por ejemplo, la española, para tratar de asegurar los espacios de desarrollo individual a partir del reconocimiento de intereses colectivos reflejados a favor de los individuales. Esa solidaridad o fraternidad abandonada desde los revolucionarios franceses es la llamada para encontrar una protección de la autonomía individual.

La solidaridad o fraternidad reflejará para Jesús González Amuchastegui (1994), “el compromiso de la comunidad por garantizar a todos" (página 51), el estatus de miembros plenos por la vida autónoma y digna, donde el Estado y sus integrantes no dejarán abandonados a los individuos para el desarrollo de sus libertades, sino que contribuirían a su realización como parte de su responsabilidad y corresponsabilidad. La necesidad de la "época puede ser definida más que nunca, como especialmente necesitada de una recuperación del concepto de solidaridad" (De Lucas, 1993, página 10), para evitar la miseria y pretender la máxima protección del hombre y la mujer a partir de los derechos humanos.

La recuperación del concepto de solidaridad en el plano del derecho implica y justifica que, como valor sea compatible, siguiendo a Gregorio Peces-Barba (1995): "con toda la tradición moral que ha configurado la idea de los derechos" (275), para alcanzar la armonía frente a la libertad y la igualdad. Una armonía dirigida a orientar y organizar, el poder público $\mathrm{y}$ las relaciones sociales humanas, con el fin de cumplir con la meta trazada por los derechos humanos de asegurar la autonomía de todos los individuos. La solidaridad en su papel de orientador en las relaciones humanas, fortalecerá las acciones dispuestas para satisfacer las necesidades básicas de todos los individuos. El derecho deberá, por lo tanto, además de reconocer la libertad a los seres humanos, facilitarles los medios o el bienestar social para que puedan en realidad alcanzarla (De los Ríos Urruti, 1926; Díaz, 1987). Esos medios serán producidos por los individuos, quienes, por intermedio de la organización y guía del Estado, buscarán satisfacer los bienes comunes básicos, y así, los individuales.

La solidaridad se presentará, por un lado, en las relaciones sociales humanas para la obtención de la satisfacción de bienes comunes, y por otro lado, para indicarle al Estado cómo organizarse para que los intereses individual y colectivo se cumplan, y aseguren la libertad en sociedad. Este artículo estará enfocado entonces en analizar la construcción del concepto propio de solidaridad de Jesús González Amuchastegui desde su visión filosófica del derecho, la cual propone para ser acogida por los Estados modernos en aras de garantizar la libertad individual, y así, los derechos humanos una razonada justificante de fundamento. Este trabajo gira en torno a la obra de este autor, pues sus investigaciones han estado inmersas en el tema de la solidaridad desde el enfoque del derecho o inspirado por ella y ha sido referente de otros tratadistas en el tema como PecesBarba (1991), De Lucas (1996), Amuchastegui (1996), dada su construcción. 
de Jesús González Amuchastegui

The concept of solidarity from the philosophical thought of the law

of jesús gonzález amuchastegui

La pregunta de investigación orientadora de este trabajo será: ¿cuál es la construcción del concepto de solidaridad desde el pensamiento de la filosofía del derecho de Jesús González Amuchastegui? Para dar respuesta al interrogante planteado, se trazó un objetivo partiendo de la hipótesis de la posibilidad de su fundamentación en el autor, el cual va analizar la construcción del concepto de solidaridad desde el pensamiento de la filosofía del derecho de Jesús González Amuchastegui.

Este objetivo permitirá diseñar una estructura básica a seguir para dar respuesta al interrogante antes señalado. En el primer apartado se estudiará la fuente del concepto de solidaridad en Amuchastegui, localizando su origen y fundamento; en el segundo apartado, se analizará el paso del individualismo posesivo al individualismo solidario de Amuchastegui, dando una explicación y razones de cómo lo hace el autor y su argumentación; en el tercer apartado, se inducirá ese individualismo solidario en el desarrollo de los Derechos Humanos, para lograrlo se adentrará a revisar los fundamentos de este último para ver la incorporación del individuo solidario; en el cuarto apartado, se expondrá el concepto de solidaridad al cual llegó Amuchastegui como la forma de justificar obligaciones de individuos para la articulación en los Derechos Humanos, revisando sus razones y analizándolas para llegar a la parte final de las conclusiones.

\section{LA FUENTE DEL CONCEPTO DE SOLIDARIDAD DE JESÚS GONZÁLEZ AMUCHASTEGUI}

La investigación inicia con el análisis y estudio de la fuente del pensamiento filosófico del derecho que permitió la construcción del concepto de solidaridad en Jesús González Amuchastegui. El profesor, en su recorrido histórico para establecer las bases hacia la solidaridad, reconoció el aporte hecho por uno de sus colegas en la filosofía del derecho, Gregorio Peces-Barba (1995), tomando la separación entre la solidaridad de los antiguos o caridad y la solidaridad de los modernos. Al igual que Peces-Barba, Amuchastegui (1994) intentó sacar a la solidaridad de la dimensión de la virtud para llevarla a la consideración de un valor superior en el ordenamiento jurídico. Para ello, se ubicó en la Francia del siglo XVIII, en un momento mencionado por
Peces-Barba como básico en la transición de la solidaridad de la virtud hacia el derecho. Amuchastegui señaló la importancia de los jacobinos socialistas, un grupo político de la revolución francesa. Este grupo se inclinó en la idea de la fraternidad como un principio de organización para las relaciones sociales, económicas y políticas, alterno al liberalismo, que estaba conectado con el egoísmo. La idea era hacer de la fraternidad o solidaridad, la perfección de la libertad individual a partir de lo social (Amuchastegui, 2004, página 533).

Amuchastegui se valió de Pierre Leroux para comprender este planteamiento, el cual se concretaba en asociación. Este autor criticaba la concepción de la sociedad como un conglomerado de individuos sujetos a sus intereses. A la vez colocaba en evidencia el peligro a surgir si se daba la relevancia a la sociedad frente a los individuos. La solución pretendida era poner en conciliación los dos extremos, al individualismo y al socialismo en una especie de compatibilidad entre la libertad y la dignidad de los individuos, frente a los intereses comunes (Sorto, 2012, página 101).

Amuchastegui centró su atención en el autor Louis Blanc para continuar con la comprensión de esa idea. Este autor socialista se enfocaba sobre el individualismo. Para Blanc, era uno de los principios divisores del mundo y la historia. Blanc proponía la sustitución del individualismo posesivo por la fraternidad o solidaridad para conducir al hombre y a la mujer a la felicidad y a la paz social (2004). Blanc (1848) comprendía el individualismo posesivo como "aquel que, abrazando al hombre fuera de la sociedad, le hace único juez de si [sic] mismo, y de cuanto le rodea, le inspira una opinión exaltada de sus derechos, sin marcarle sus deberes" (página 13). Y por el principio de solidaridad, "aquel que, considerando solidarios á [sic] todos los individuos de la gran familia, tiende á [sic] la organización de las sociedades" (Blanc, 1848, página 13). En este último pondría su apuesta teórica, en aras de estructurar mejor la sociedad y alcanzar la libertad socialista. La solidaridad en Blanc insistiría en la dimensión social de los individuos como pensamiento de la conciliación de los intereses comunes e individuales.

De los dos principios, el individualismo resultaría ganador en la época, según Blanc, 
porque respondía a los intereses de la clase dominante. A Blanc, por su intento no se le podía señalar de crítico del individualismo en general, sino del individualismo posesivo. Blanc (1848) apreciaba al individualismo como:

triunfo de la libertad de conciencia sobre la intolerancia y el dogmatismo de la Iglesia Católica; de la libertad política frente al absolutismo del Antiguo Régimen; y de la libertad de industria frente a los monopolios y trabas característicos del sistema feudal (página536).

Pero al mismo tiempo miraba lo malo, el exceso del individualismo aislado, opresor de la dimensión social del hombre y la autoridad. Para Blanc, este individualismo aislado o posesivo pretendía obviar cualquier tipo de orden, dejando al ser humano a la deriva del anarquismo $^{1}$.

Para Blanc, el individualismo posesivo podía identificarse como un tipo de libertad sin límites y restricciones, mientras que la libertad buscada por los socialistas jacobinos, como el propio Blanc, era una libertad que fusionaba el lema revolucionario francés de la igualdad y la fraternidad, una auténtica libertad donde no existe contradicción alguna entre el interés personal y el general para la defensa de los derechos individuales y sociales o de bienestar. Blanc, se convertiría en la fuente de producción intelectual seguida por Amuchastegui, como se apreciará a continuación.

\section{DEL INDIVIDUALISMO POSESIVO AL INDIVIDUALISMO SOLIDARIO DE J. GONZÁLEZ AMUCHASTEGUI}

Amuchastegui asumió el ataque al individualismo de la idea de Blanc, posicionar a la solidaridad como valor y un aporte de solución al derecho. Así, se refirió a la solidaridad como superación de la lucha competitiva, que identificaba al individualismo posesivo como el causante del exceso en el liberalismo. Para la superación, siguiendo la idea de Victoria Camps (1990), debía darse un

\footnotetext{
1 Eso recuerda el lema del ala económica del liberalismo: dejad hacer, dejad pasar, el mundo va solo (laissez-faire, laissez-passer le monde va de lui même), popularizado por los seguidores de Adam Smith, para tratar de justificar la libertad como forma para asegurar la competencia del libre mercado.
}

contrapeso al prejuicio egoísta, a ese individuo que por naturaleza era egoísta y solo se quería a sí mismo. El individuo egoísta o posesivo recordado del relato de Thomas Hobbes en su obra Leviatán, que en estado de guerra natural dependía de sus propias fuerzas para mantener su seguridad, un individuo luchador y egoísta, el cual no le importaba sino él y quien sólo aceptaba restricciones a su libertad para mantener su igualdad frente a otros. El mismo individuo descrito por Bobbio (2003), inmerso "en el mundo desconocido y lleno de peligros de la lucha por la supervivencia, donde cada cual debe velar por sí mismo, en una lucha perpetua" (412). A ese individuo posesivo contrapuso Amuchastegui, uno solidario.

Un individuo caracterizado por una fuerte sociabilidad y un natural sentimiento de simpatía para combatir al egoísmo. La implementación del individuo solidario pasaba por restaurar en los seres humanos la idea de que en sociedad, se garantizaba a todos el desarrollo individual de libertad, y para lograrlo, el sentimiento natural de simpatía jugaría un papel a favor de las relaciones sociales. La idea del autor, con estas dos reivindicaciones, era conciliar al individualismo y la sociedad para el terreno de las exigencias de la libertad en los derechos humanos, porque el individuo desarrollaba su libertad al interior de la sociedad, mientras el derecho apuntaba a su garantía. Para Amuchastegui (2004), la comunidad liberal en la que se integraba el socialismo y su individuo solidario no asumía la incompatibilidad de los intereses críticos individuales y los intereses comunes de la sociedad. Los intereses críticos de un individuo se harían primar o armonizar con los intereses comunes, dependiendo de si era solidario o egoísta, o en palabras que recuerda Amuchastegui de Jean-Jacques Rousseau, si los hombres y mujeres actuaban bajo el amor de sí mismos o con amor propio.

El amor del hombre por sí mismo, según Rousseau (1999): “es un sentimiento natural que lleva a todo animal a velar por su propia conservación, y que, dirigido en el hombre por la razón y modificado por la piedad, produce $o$ engendra el sentimiento de humanidad y el de virtud" (página 125), es el instinto de conservación que rodea a los hombres y mujeres como forma de su reconocimiento y el de los demás para cuidar "de sí y de sus allegados"(Carracedo, 2008, página 249), una base de la organización social y una condición 
de Jesús González Amuchastegui

The concept of solidarity from the philosophical thought of the law

of jesús gonzález amuchastegui

para el progreso, según Amuchastegui. Por el contrario, el amor propio de un individuo es un sentimiento de desahucio al antes mencionado, su degeneración debido a la inclinación por el extremo del yo, "que conduce a cada individuo a apreciarse más que a los demás" (Rousseau, 1999, página125). Para Amuchastegui produce la desintegración social y la mayoría de sus vicios, como resultado de la afirmación de la propiedad privada y la desigualdad. Un amor propio que "sabe que no puede ser satisfecho, y odia a los demás por su propio amor" (De Benoist, 1971, página 8), es, al fin, el yo egoísta, antepuesto a toda consideración que despierta la competencia recia, violenta y arbitraria entre los hombres y mujeres, y los lleva a sobreponer sus intereses críticos frente a los comunes (Carracedo, 2008, página 249).

El individuo con amor por sí mismo es aquel, el cual el progreso de la comunidad le preocupa por su instinto de conservación, a quien le importan los intereses individuales y comunes. Ese individuo con amor por sí mismo y solidario, reconocerá y aportará a los bienes colectivos, mientras se va desarrollando como resultado de la conciliación. El individuo solidario de la propuesta de Amuchastegui va a asumir la responsabilidad moral individual y permitirá, la lucha y la defensa para los derechos humanos. Será el mismo objetivo propuesto por Blanc, respecto a armonizar la libertad y la sociedad por intermedio de la solidaridad. La defensa del individuo solidario o la solidaridad al interior de los derechos humanos por parte de Amuchastegui, estará encaminada a replantear su eje fundamental, el individualismo ${ }^{2}$ como componente para alcanzar el progreso de la libertad en todos los seres humanos.

\section{EL INDIVIDUALISMO SOLIDARIO O LA SOLIDARIDAD EN EL DESARROLLO DE LOS DERECHOS HUMANOS}

El traspaso de la solidaridad como virtud al derecho, conlleva a Amuchastegui a una fuerte defensa para demostrar como beneficiará a los seres humanos en la posibilidad de alcanzar

\footnotetext{
2 Sobre el particular Fernández (2004) ha señalado: "creo que un logro moral de la historia de la humanidad, que es la construcción de la tesis del individualismo moral, es decir, de la defensa clara de la superioridad moral de las personas individualmente consideradas. Esta tesis se ha convertido en un presupuesto moral y teórico de cualquier teoria de los derechos humanos fundamentales" (página 216).
}

la libertad. La solidaridad en Amuchastegui conduce, por intermedio del individuo solidario, a ver a los derechos humanos de manera distinta, como garantía y protección del individuo. La partida de Amuchastegui, respecto a que todas las teorías de los derechos humanos tienen como base al individuo, es la razón para tomar al individualismo posesivo y reemplazarlo por el individualismo solidario. Bajo esta idea, Amuchastegui enseñará como en el derecho, los individuos entre sí, enfrentaran, desde la solidaridad como valor, los problemas que afectan a la libertad.

Los derechos humanos al centrarse en el individuo buscan garantizar la autonomía o la libertad. La autonomía individual a proteger, se puede comprender, siguiendo a Amuchastegui de la noción canónica de John Stuart Mill, no interferencia de terceros o el Estado. En palabras textuales de Mill (1859): "ningún hombre puede en buena lid, ser obligado a actuar o abstenerse de hacerlo" (página 26). La visión de Mill en cuanto a la autonomía, estaba orientada en que el individuo era dueño de su destino y no se le podía imponer prohibiciones o sanciones en contra de su voluntad, a menos que causara un daño a terceros. La autonomía individual como principio permitió, la fundamentación de derechos de libertad. Para Amuchastegui, esta resultaría compleja en relación con los derechos de bienestar. En la concepción solidaria del socialismo de Amuchastegui, era importante la conexión entre autonomía individual y bienestar, para comprender la responsabilidad colectiva de los individuos solidarios.

Para lograr la conexión, Amuchastegui analizó si la autonomía individual, como meta de los derechos humanos, se encontraba asegurada en el derecho al solo imponer límites a terceros. Esta condición no tenía en cuenta otros factores relevantes que alteraban la autonomía. Según Amuchastegui, un ejemplo era la pobreza. Diferente a los límites impuestos a terceros, la pobreza alteraba el orden de la autonomía y causaba daño, porque la ausencia de condiciones económicas, sociales, culturales, etcétera, supeditaban a su satisfacción el desarrollo de la voluntad del individuo. Otro ejemplo en el que se puede apreciar es la discapacidad ${ }^{3}$. El daño

3 El tema de la discapacidad en relación con la autonomía es interesante, porque muestra las dificultades reales a las que se enfrenta la figura. La discapacidad no puede entenderse como un problema físico, mental, entre otros, como se había 
a la autonomía en la discapacidad ${ }^{4}$ es producto de múltiples factores, entre ellos, social, físico e intelectual, y con la sola limitación de la actividad de terceros o del Estado en la norma no se eliminan. La idea de Amuchastegui torna por vincular a la autonomía individual, las necesidades básicas. Para el ejercicio de la autonomía debe, además de limitar la actividad de terceros, suplir unos bienes primarios o satisfacer necesidades humanas básicas y permitir así, los individuos puedan actuar a su libre voluntad, sin estar condicionados.

Amuchastegui desarrolló un poco más la idea y observó necesario: primero, replantear la noción de daño del liberalismo conservador; segundo, justificar la satisfacción de necesidades básicas humanas como condición de la autonomía.

Respecto a la noción restrictiva de daño de la concepción liberal conservadora, entiende que, se encuentra enlazada al resultado de una acción positiva, comprendiendo por ella, empeorar o transformar una situación en negativa. Esto es, para producir un daño sobre la autonomía de un individuo, los terceros deben realizar una acción o actividad. De allí que, el derecho derive normas jurídicas para proteger la autonomía individual utilizando la coerción para "evitar que una persona le haga daño a otra persona" (Appiah, 2007, página 67). El daño es producto de la acción, pero, Amuchastegui defiende la incorporación de la omisión como otra forma de generar daño. La mujer u hombre pueden dañar a otro no sólo

sostenido en la historia, y como lo enseñaran los distintos modelos teóricos de la discapacidad que estudió Agustina Palacios (2008). Así, el modelo de la prescindencia, que recogía. a su vez, dos sub-modelos, el eugenésico y el de marginación; en los que las personas con discapacidad eran rechazadas o repudiadas por la comunidad. Y el modelo rehabilitador o médico; conforme al cual la discapacidad se intentaba corregir o adaptar a los estándares y exigencias de la sociedad. Los dos modelos mencionados violaban de forma directa la autonomía individual, la cual, sin embargo, era teóricamente respaldada por los mismos sistemas jurídicos. El modelo actual, que intenta ser plenamente respetuoso con la autonomía de las personas con discapacidad, es el social, en el que se empieza a ver a la discapacidad como una cuestión de derechos humanos.

4 La definición de discapacidad se encuentra recogida en la Convención sobre los Derechos de las Personas con Discapacidad, artículo $1^{\circ}$ : "El propósito de la presente Convención es promover, proteger y asegurar el goce pleno y en condiciones de igualdad de todos los derechos humanos y libertades fundamentales por todas las personas con discapacidad, y promover el respeto de su dignidad inherente. Las personas con discapacidad incluyen a aquellas que tengan deficiencias fisicas, mentales, intelectuales o sensoriales a largo plazo que, al interactuar con diversas barreras, puedan impedir su participación plena y efectiva en la sociedad, en igualdad de condiciones con las demás". con su acción o actividad, sino también con su omisión o inactividad. Verbi gratia, podría imaginarse que una persona con pérdida de movilidad en su cuerpo necesita tomar unos medicamentos de una estantería, los cuales son esenciales para permanecer con vida y sin embargo, no puede acceder a ellos. Un individuo se percata de la situación y no hace nada para alcanzárselos, dejándolo a la deriva. En el ejemplo, se puede evidenciar una omisión del agente al no alcanzar los medicamentos a otro, lo cual se traduce en un desmedro para la autonomía individual. La razón consiste en que los medicamentos son un bienestar para el individuo, al no consumirlos su salud estaría afectada hasta llevarlo a la muerte.

El ejemplo alrededor de la acción o actividad como noción de daño mantenida por la concepción liberal conservadora, cambiaría totalmente de contexto. El agente no participa en alcanzar el medicamento y el resultado de daño no le es atribuible, pues no generó ningún tipo de acción. En un caso como el anterior, al reformular la noción de daño e integrar la omisión, sería fácil atribuirle la responsabilidad del resultado a un tercero, porque el sujeto o el Estado al dejar de realizar algo para contribuir en la autonomía de otro, genera daño. Como el anterior, existen muchos más ejemplos donde la inactividad de terceros o el Estado, convierten su conducta en menoscabo para la autonomía de otros sujetos, y habrá otros donde no sean tan evidentes los daños por omisión, al ser graduales o parciales, pero en los que al final, se deteriorará igualmente, la autonomía individual.

La omisión para Amuchastegui (2004) es "una injerencia pasiva" (página 524), o inactividad del individuo frente a la existencia de un daño. La pretensión del autor pasa por adherir al resultado otra causante. No solo existirá la acción o actividad, sino también la omisión o inactividad por parte del ser humano para producir, modificar o no "evitar que un mal se produjera o permitir que continuara" (Amuchastegui, 2004, página 524). En Amuchastegui no existe ningún problema teórico para exponer que, no contribuir para satisfacer necesidades básicas es una omisión de daño para la autonomía individual. Por tanto, los poderes públicos, además de limitar a las personas en sus libertades para que no afecten a otros por sus acciones, deben hacerlo al igual con las omisiones. Para 
de Jesús González Amuchastegui

The concept of solidarity from the philosophical thought of the law

of jesús gonzález amuchastegui

ello, Amuchastegui intentará justificar la satisfacción de necesidades básicas humanas como condición de la autonomía individual.

En cuanto a la justificación de la satisfacción de necesidades básicas humanas como condición de la autonomía, Amuchastegui parte de la idea de que, el hombre y la mujer no pueden desarrollarse de forma libre si sienten la presión de las necesidades humanas básicas para ser satisfechas, con lo cual, se convierten en una precondición para alcanzar la libertad -la autonomía de vida-. La autonomía, un bien valioso en sí mismo para Amuchastegui, existe "al margen de las preferencias subjetivas de los individuos" (Amuchastegui, 2004, página 524), concurren parámetros objetivos para la identificación y jerarquía de bienes instrumentales para el desarrollo de la autonomía de los individuos. Esos bienes son llamados por el autor, básicos o primarios.

Los bienes básicos reúnen todas las características generales para potencializar a todos los seres humanos sin importar sus preferencias. Por tanto, implica, regirse por el principio de la precedencia o prioridad de las necesidades. Un principio que expone, la prioridad de las necesidades de los individuos frente a sus preferencias (Riechmann, 2005, página 157; Attfield, 1995, página 93).

Un individuo puede necesitar atención médica, pero a cambio de no gastar los pocos ahorros, prefiere no acudir a la asistencia sanitaria. El intento es identificar las necesidades humanas básicas primarias y jerarquizarlas, ponerlas por encima de cualquier preferencia individual, buscando asegurar, primero, la satisfacción de necesidades primarias o básicas humanas $\mathrm{y}$, segundo, llevar al disfrute de las preferencias individuales.

Amuchastegui toma estas dos ideas como la justificación del derecho moral para satisfacer a todos los seres humanos sus necesidades básicas, las cuales están a cargo del Estado. El deber del Estado no sólo estará trazando los límites a la injerencia de terceros, sino además, ofreciendo todos los medios necesarios para el disfrute de las necesidades básicas, por lo que tendrá que, valerse del valor de solidaridad o el individuo solidario para organizar y dar su cumplimiento. Al alcanzar Amuchastegui, la conexión entre autonomía y necesidades básicas, expone que, para lograr un disfrute total de la autonomía por parte de los individuos deben estar satisfechas las necesidades $o$ al menos, brindarles las herramientas para lograrlo. La satisfacción de las necesidades o proporción de las herramientas para hacerlo, es responsabilidad del Estado, pero a raíz de su insuficiencia, el individuo solidario, como parte de éste, deberá sopesar los bienes básicos o los intereses comunes, aportando para ser alcanzada por cada uno, la autonomía individual.

La propuesta de Amuchastegui de vincular al daño la acción y la omisión, hace parte de su intento porque los individuos dejen de lado el egoísmo, restaurando las relaciones sociales para garantizar el progreso de la libertad. Los individuos en su actuar u omitir podrán estar dañando la autonomía de otros. Por eso, el individuo solidario, al reconocer los intereses colectivos o bienes básicos conciliados con los propios en la dimensión social, deberán tener un compromiso para participar satisfaciendo necesidades humanas básicas y asegurar la libertad de todos, contribuyendo al objetivo común. Al individuo solidario le surgirán nuevas obligaciones por la organización del Estado, esto, para poder cumplir la meta de los derechos humanos.

En el siguiente apartado se mirará, como Amuchastegui conceptúa a la solidaridad, mientras la incorpora al análisis del tipo de obligaciones que los derechos humanos justificadamente pueden adscribir a terceros, luego de comprender el rol del individuo solidario y del Estado.

\section{EL CONCEPTO DE SOLIDARIDAD DE AMUCHASTEGUI COMO JUSTIFICANTE PARA LAS OBLIGACIONES DE LOS INDIVIDUOS EN LOS DERECHOS HUMANOS}

El profesor Amuchastegui pretende, a través del individuo solidario o la solidaridad, cumplir con el objetivo de los derechos humanos: proteger y garantizar la autonomía individual. Poner en armonía, la libertad y la sociedad por medio de la solidaridad, un discurso teórico del liberalismo social. El autor entiende por solidaridad, aquella por la cual el Estado se valdrá para su organización del individuo. Para Amuchastegui (2004), la solidaridad es 
la "superación de la lucha competitiva por la supervivencia y el reconocimiento de una responsabilidad colectiva en la satisfacción de las necesidades básicas de todos los miembros de la comunidad" (página531).

La solidaridad para Amuchastegui estará presente donde el Estado, mediante su fuerza de organización, orientará su actividad para la satisfacción de las necesidades básicas por medio del individuo solidario, quien es el llamado a superar la lucha competitiva al tiempo que acepta la responsabilidad de los intereses colectivos para el progreso individual de la autonomía.

La aceptación del individuo solidario para alcanzar la satisfacción de necesidades básicas humanas para todos produce compromisos colectivos e individuales frente a otros y frente al Estado. Bajo este concepto, a Amuchastegui le pareció válida la aproximación de la Real Academia Española de la Lengua (2001), en cuanto a que, ser solidario era adherirse a la causa, empresa u opinión de terceros. Sin embargo, inserta un matiz Amuchastegui, un individuo debía contribuir a los demás no de manera abierta y en todo, sino restringida, sólo en la satisfacción de las necesidades humanas básicas.

Los intereses de otros no implica asumirlos de manera necesaria, por completo y en todos los sentidos, sin horizonte alguno, sino de aquellos para los cuales, los bienes primarios no estuvieran garantizados, siempre que no se pusieran en peligro los propios bienes primarios, porque de nada valdría la imposición de un deber u obligación sin tener como hacerlos efectivos (Amuchastegui, 1991). Las obligaciones a terceros pretenden asegurar la satisfacción de unas necesidades básicas de los seres humanos para proteger el progreso de la autonomía individual. Pero entonces, ¿qué tipo de obligaciones podrían los derechos humanos justificadamente adscribir a terceras personas? La respuesta a este interrogante es abordada para Amuchastegui, al reconocer que los derechos de los individuos justifican deberes y objetivos colectivos para ser dispuestos por el poder público.

La pregunta para Amuchastegui tiene un trasfondo alrededor de la delimitación de los derechos o mejor, de cuáles son las exigencias de los derechos para su desarrollo.
Amuchastegui le dio respuesta a la cuestión por medio de un debate que recreó al interior del liberalismo, y para quien la concepción de los derechos humanos era netamente liberal. Antes de continuar, una aclaración. El debate se incorporará para permitir ver, aparte de dar respuesta al interrogante, cómo Amuchastegui pone en acción el concepto de solidaridad dentro del derecho y por intermedio de la justificación de deberes u obligaciones.

El debate se presenta entre el liberalismo conservador y el liberalismo socialista o socialismo. Este último es, donde se inscribe Amuchastegui. La concepción liberal conservadora y la liberal socialista tienen distintas posturas respecto a, cuáles son las exigencias de los derechos para ser desarrollados, así, se logra establecer a raíz de las respuestas a las preguntas elaboradas por Carlos Santiago Nino y analizadas por Amuchastegui. En resumen, vendrían a ser: si el Estado debía abstenerse de lesionar de manera activa, bienes o derechos y prohibir a los particulares lo mismo, o si el Estado debía proveer condiciones necesarias para preservar los bienes y obligar a los particulares (Amuchastegui, 2004, página 531).

Bajo estos interrogantes, Amuchastegui revisó las posturas de Carlos Nino y concluyó que, el punto álgido de la problemática eran las obligaciones o deberes activos $\mathrm{y}$ pasivos, o positivos $\mathrm{y}$ negativos. Para los liberales conservadores, los derechos derivan obligaciones pasivas o negativas "de modo que su violación es necesariamente una conducta activa" (Nino, 1989, página 315). Los terceros o el Estado no están obligados a realizar acciones que interfieran en contra de otros, evitando así, el daño. Para el liberalismo socialista en cambio, los derechos derivan tanto obligaciones activas como pasivas. Las obligaciones activas implican una interferencia justificada a terceros o el Estado para evitar un daño a otro.

Los liberales conservadores discrepan de los socialistas según Amuchastegui, porque consideran con problemas la justificación de obligaciones positivas en dos puntos: primero, la incierta conexión entorno al comportamiento exigido o deseado y el derecho humano sustentado al descansar en un concepto de daño discutible. Para los liberales conservadores, una conducta positiva, socorrer o auxiliar a 
de Jesús González Amuchastegui

The concept of solidarity from the philosophical thought of the law

of jesús gonzález amuchastegui

alguien por ejemplo, viene a ser obligatoria si al incumplirla se genera un daño. Esto sería falso, piensan los conservadores, pues el daño podría producirse por otros factores. Lo erróneo, de forma simple, es afirmar que quienes no auxilian a otros están dañando al tercero. La idea es poner en evidencia las distintas formas de causar daño a un individuo, y que no por ello los terceros sean, por el hecho de obligarse a contribuir, los responsables del desmedro. El segundo punto de la discrepancia es ampliar más las restricciones a la libertad con las obligaciones positivas. Convertir a un individuo en responsable de un daño cuando deja de hacer u omite una disposición de protección a un bien.

Amuchastegui, en cuanto al primer punto, recordó su reformulación de daño y apuntó que debía asumirse por la concepción liberal conservadora. No podía entenderse el daño solo como el resultado de una acción positiva que transformara una realidad o situación en negativa. El daño implica también evitar el generar un mal o permitir que continúe en una situación o circunstancia. Ambas repercuten en la autonomía de un individuo. Lo que se quiere, al reformular la noción de daño y dar paso a obligaciones positivas, es vincular a los individuos solidarios a contribuir para prevenir o evitar las lesiones a la autonomía. Su acción u omisión pueden llegar a generar riesgo o pérdida. En el caso de auxiliar a un herido de un accidente, los intentos de los terceros estarán encaminados a evitar la pérdida de vida, así no hayan producido la acción. Su contribución será la de satisfacer una necesidad básica humana, para el caso expuesto, la vida.

En relación al segundo punto, para Amuchastegui es cierto que las obligaciones positivas restringen más la libertad en comparación con las obligaciones negativas. Las obligaciones positivas son incumplidas por la omisión. Según Amuchastegui, si un individuo está obligado a dar alimentos a su hijo no puede quedarse sin hacerlo, estaría incumpliéndola. Solo existiría un modo de efectuar la obligación: realizar la conducta o mandato. Las obligaciones negativas en cambio son incumplidas por acción. Matar a otro conlleva realizar la acción. El individuo puede desarrollar una gran cantidad de conductas y sólo se le prohíbe una para incumplir la obligación. Lo anterior lleva a deducir que no todas las restricciones hechas por las obligaciones positivas serán ilegítimas.
Para el autor, en realidad de lo que se trata es de indicar hasta dónde se puede restringir la libertad y sus razones.

Amuchastegui aceptó lo difícil de la problemática y sin embargo ofreció algunas consideraciones para lograr ese límite admisible en la libertad desde la solidaridad: a) Reconocer que no es cierto que toda restricción a la libertad sea injustificada, la libertad como derecho no es ilimitada; b) si el objeto de cualquier ética normativa, siguiendo a Garzón Valdés, es asegurar la protección de bienes valiosos, y para hacerlo se disponen deberes generales a terceros, no existe razón para limitar los negativos o positivos, ambos buscan proteger los bienes 5 ; c) las obligaciones positivas deben alcanzar lo universal o general; d) de lo anterior se deduce que no se intenta que se cumplan de forma individual, sino que debe darse una articulación a nivel institucional o por el Estado para llevar a cabo acciones de bienestar desde el cumplimiento de los deberes positivos; e) la concepción de los derechos humanos como exigencia de garantía universal para la satisfacción de necesidades básicas debe valerse de actos moralmente obligatorios (actos que se deben ejecutar sin apremio alguno y que de no realizarse se produciría una sanción), y no de actos supererogatorios (aquellos actos donde no existe "obligatoriedad ni tampoco prohibición. Además, su omisión no puede ser considerada como algo moralmente incorrecto $\mathrm{y}$, por lo mismo, no merece sanción ni crítica formal o informal" (Álvarez, 2007, página 236), pero cuando se realizaran, tendrían un merecimiento o premio) ${ }^{6}$. Adoptar los actos moralmente obligatorios llevaría a adoptar un único modelo de vida, el del buen samaritano plantea Amuchastegui, pues deja atrás la autonomía de vida individual para asumir actos heroicos o, como exponía Peces-Barba, actos virtuosos.

\footnotetext{
5 Para Garzón Valdés (1986): "Deberes positivos generales son aquéllos cuyo contenido es una acción de asistencia al prójimo que requiere un sacrificio trivial y cuya existencia no depende de la identidad del obligado ni de la del (o de los) destinario(s) y tampoco es el resultado de algún tipo de relación contractual previa" (página 17). De esto se desprende el intento de Garzón Valdés de perfilar los distintos puntos críticos y debates importantes, para pasar a justificar, desde lo moral, los deberes positivos, llegando al punto, compartido por Amuchastegui, de que tanto los deberes negativos como los positivos son equiparables.

6 Esta posición de los actos supererogatorios se puede ampliar con las explicaciones que ofrece Urmson, cuando pone a discusión los deberes morales afrontados por los hombres, en su mención de los actos de los santos y los héroes (Urmson, 1985).
} 
¿Dónde estaría la línea divisoria entre lo obligatorio y lo virtuoso, o lo moralmente exigible y lo supererogatorio? Responde Amuchastegui que las obligaciones individuales no deben traducirse en una variedad de iniciativas aisladas, sino que deben coordinarse por parte del Estado para lograr los proyectos colectivos. De esta manera, se establecería cual es la contribución que cada individuo debe realizar sin pasarse al ámbito de la virtud.

Bajo estas consideraciones, para limitar de forma justificada la libertad por intermedio de obligaciones positivas, Amuchastegui conecta la idea de que en definitiva el Estado sin la ayuda de los integrantes no podría satisfacer las necesidades básicas humanas a todos y no se podría hablar de que son igualmente autónomos ${ }^{7}$. Los particulares son los únicos capacitados para sufragar las necesidades básicas de los demás, a ellos tendría que acudir el Estado para proporcionarlas. Esa es la razón para Amuchastegui de incorporar la solidaridad como el medio de conciliación entre intereses particulares y colectivos.

El Estado, al asumir a la solidaridad como valor, podría ser un intermediario para organizar la sociedad, alcanzar el fin de los derechos humanos y tomar una tarea de redistribución. Para cumplir con el fin de la autonomía para todos, debe contar con determinados bienes y recursos para satisfacer las necesidades básicas, estos serían cubiertos por los individuos. No obstante, esa posición condujo a un cuestionamiento desde la concepción liberal conservadora, y se podría decir, es la adoptada por todos aquellos defensores de la libertad más pura y estricta.

¿Se justificaría por los derechos humanos la exigencia de obligaciones a terceros? Desde luego para Amuchastegui se justificaría siempre y cuando se beneficiarán los que peor

\footnotetext{
7 Como una pequeña aclaración, se podría decir, el autor, al parecer, tenía una visión del Estado como ente con personalidad abstracta. Y aunque pudiera dar lugar a disputa esta posición, solo quisiera recordar que si bien la escuela realista escribia sobre que la calidad de personalidad era sólo atribuible a los seres humanos y no al Estado u objetos, mientras la tesis contraria, la escuela de la ficción, daba lugar a la personalidad del Estado, el Estado debía entenderse, y como lo hace el autor, limitado por sus integrantes. Son los seres humanos quienes le dan representación o animación por ficción a esa teoría llamado Estado, y por tanto, cuando se refiere al mismo se está mencionando a su población en conjunto, a todos los miembros, y no se quiere decir con ello que, el Estado no tenga su finalidad, por el contrario, está dispuesto para servir a los individuos (Santofimio, 1994, página 31).
}

estuvieran antes de realizar la redistribución y no se le redujera al nivel de estos a los afectados después de implementadas las medidas de obligación. Su explicación se adecúa al objeto o fin que tienen los derechos humanos. La garantía a todos los individuos de un conjunto de capacidades iguales de bienestar para asegurar la autonomía y poder ratificar que son los dueños de sus destinos. Este argumento de Amuchastegui logra favorecer la justificación de obligaciones a terceros desde su concepto de solidaridad y alejar dos posibles contra argumentos: uno, que las obligaciones toman a los individuos afectados como medios y no fines en sí mismos; y dos, que las obligaciones son una posible afectación al principio de dignidad e inviolabilidad de la persona.

Los dos contra argumentos son muy loables para refutar la concepción solidaria del socialismo de Amuchastegui, pues señalaban la posibilidad de asumir la instrumentalización de los hombres para satisfacer las necesidades de otros. Una idea conectada con la filosofía utilitarista de Jeremy Bentham (1996), la cual buscaba alcanzar la mayor felicidad o placer del mayor número de ciudadanos, valiéndose de la utilidad, afectación o dolor a unos pocos para obtener el mayor bien. En el caso de la solidaridad, supondría imponer obligaciones a unos para garantizar autonomía a todos, conduciendo un detrimento al principio de dignidad de la persona. Debía tenerse en cuenta como defensa, según Amuchastegui, que la distribución natural de capacidades, bienes y talentos de las personas no justificaban moralmente, en todo caso, las consecuencias derivadas de ellas en relación con las desigualdades, perdidas de libertades y reducción en la autonomía, porque era un dato modificable desde la actividad política para implementarse en el derecho.

El dato natural de la distribución y sus consecuencias no tendrían que ser asumidos ni obedecidos por la política, Amuchastegui (2004) fue claro: "no es verdad que los seres humanos tengamos un derecho absoluto a disfrutar ilimitadamente de todos los bienes que hemos recibido de la naturaleza" (página 548). La redistribución tomaría de unos bienes individuales para incentivar a otros mermados por condiciones naturales, accidentales $\mathrm{o}$ sociales en sus capacidades, permitiendo alcanzar un desarrollo de la autonomía en general. 
de Jesús González Amuchastegui

The concept of solidarity from the philosophical thought of the law

of jesús gonzález amuchastegui

Las obligaciones positivas en el derecho llevarían a la ejecución de esa redistribución. Surge a raíz de lo anterior un nuevo problema: ¿cuál sería el límite para la actuación de los poderes públicos a la hora de implementar las políticas redistributivas de bienes, derechos y obligaciones? La respuesta ofrecida por Amuchastegui es: hasta donde se alcance la garantía de las capacidades a todos los individuos como objetivo de la redistribución determinada por la autonomía.

\section{CONCLUSIONES}

La construcción del concepto de solidaridad de Jesús González Amuchastegui, como se observó en su origen, fuente, raíces y elementos relevantes, lleva a concluir que: al igual que Peces-Barba, Amuchastegui trató a la solidaridad en la dimensión del derecho. La fuente para construir su concepto de solidaridad provino de Louis Blanc. Este autor, de ideales socialistas implantó en Amuchastegui la defensa de la dimensión social de los individuos para llevar a la conciliación de los intereses particulares y los intereses colectivos, una armonía entre libertad, sociedad y fraternidad o solidaridad.

El concepto de solidaridad de Amuchastegui es una clara oposición al prejuicio egoísta o individualismo posesivo, supone la superación de la lucha competitiva por la supervivencia. El concepto de solidaridad de Amuchastegui desarrolla un individuo solidario, reivindicándosele una noción fuerte de sociabilidad y un natural sentimiento de simpatía, se opondrá al individuo posesivo y aceptará la responsabilidad moral individual para alcanzar y satisfacer metas comunes. La solidaridad en Amuchastegui conduce a los hombres y mujeres en un vínculo para desarrollar fines comunes, materializándose así los propios.

Amuchastegui, para su construcción de solidaridad, condicionó el alcance de la autonomía individual a la satisfacción de las necesidades básicas humanas, responsabilizando al Estado y a los terceros de su protección. De esta manera, la solidaridad, como concepto construido, se presentó ante el Estado como un valor para organizar las relaciones sociales, el poder público y su actividad, pretendiendo que fueran satisfechas por todas las necesidades básicas humanas, y así garantizar la autonomía a los individuos.
El concepto de solidaridad de Amuchastegui da cuenta de la imposibilidad de satisfacer todas las necesidades básicas por parte del Estado y, por tanto, asocia a los individuos por medio de las obligaciones positivas y negativas como derivación de los derechos. Las obligaciones están encaminadas para evitar daños a la autonomía, sean por acción u omisión, conforme a la reformulación de la noción de daño de Amuchastegui.

El autor, en apariencia logró justificar que, si bien las obligaciones positivas limitaban más la libertad que las obligaciones negativas, ambas tenían por fin proteger bienes valiosos, siendo legítima su imposición para beneficiar a los que peor estuvieran en la sociedad y no se les redujera a los obligados al nivel de aquéllos. Las obligaciones buscaban garantizar a todos los individuos capacidades iguales de bienestar para lograr la autonomía, todo a partir de la solidaridad.

\section{FUENTES DE INFORMACIÓN}

\section{Fuentes bibliográficas}

Amuchastegui, J.G. (1994). Solidaridad y derechos de las minorías. en L.P Sanchís. Derechos de las minorías y de los grupos diferenciados, serie solidaridad, núm. 6. (147160). Madrid, España: Editorial Escuela Libre.

Amuchastegui, J.G. (1996). Mujer y derechos humanos: concepto y fundamento. En M. Ramos (Ed). Derechos humanos de las mujeres: aproximaciones conceptuales. (9-51). Lima, Perú: Editorial Movimiento Manuela Ramos.

Amuchastegui, J.G. (2004). Autonomía, dignidad y ciudadanía. Una teoría de los derechos humanos. Valencia, España: Editorial Tirant lo Blanch.

Appiah, K.A. (2007). La ética de la identidad, Trad. Lilia Mosconi, $1^{\mathrm{a}}$ ed. Buenos Aires, Argentina: Editorial Katz.

Attfield, R. (1995). Value, obligation and meta-ethics.Value inquiry book. Amsterdam, Paises Bajos: Editorial Rodopi.

Bentham, J. (1996). An introduction to the principles of morals and legislation. Oxford, Reino Unido: Clarendos Press. 
Blanc, L. (1848). Historia de la revolución francesa. Tomo 1. Trad. Fernando Madoz. Madrid, España: Editorial Imprenta del diccionario geográfico a cargo de José Rojas.

Bobbio, N. (2003). Teoría general de la política. Trad. Antonio De Cabo y Gerardo Pisarello, Ed., Michelangelo Bovero. Madrid, España: Editorial Trotta.

Camps, V. (1990). Virtudes públicas. Madrid, España: Editorial Espasa-Calpe S.A.

De Lucas, J. (1993). El concepto de solidaridad. $1^{\mathrm{a}}$ ed. Ciudad de México, México: Editorial Fontamara.

Díaz, E. (1987). Humanismo y socialismo en Fernando De Los Ríos. En F.R. Rodríguez (Ed). Estudios en honor del doctor Luis Recaséns Siches. Tomo II, (199-206) Ciudad de México, México: Editorial Instituto de Investigaciones Jurídicas de la UNAM.

García, E.F. (2004). Los derechos humanos y la historia. En L.P. Ramón (Ed). Constitución $y$ derechos fundamentales, $1^{a}$ ed. (215-234). Madrid, España: Editorial Ministerio de la Presidencia, Secretaría General Técnica, Centro de Estudios Políticos y Constitucionales.

Nino, C.S. (1989). Ética y derechos humanos. Un ensayo de fundamentación, $2^{\mathrm{a}}$ ed. Buenos Aires, Argentina: Editorial Astrea de Alfredo y Ricardo Depalma.

Palacios, A. (2008). El modelo social de discapacidad: orígenes, caracterización y plasmación en la Convención Internacional sobre los Derechos de las Personas con Discapacidad, $1^{\text {a }}$ ed. Colección CERMI núm. 36. Madrid, España: Editorial Grupo CINCA.

Peces-Barba, G. (1995). Curso de derechos fundamentales. Teoría general, colaboración de R. Asís, C. Fernández Liesa y A. Llamas. Madrid, España: Editorial Boletín Oficial del Estado - Universidad Carlos III.

Peces-Barba, G. (1991) Humanitarismo y solidaridad social como valores de una sociedad avanzada. en R.L. García (Ed). Las entidades no lucrativas de carácter social y humanitario. (15-62). Madrid, España: Editorial La Ley y Fundación ONCE.
Riechmann, J. (2005). Un mundo vulnerable. Ensayos sobre ecología, ética y tecnociencia, Pról. Joaquín Gallego, $2^{\mathrm{a}}$ ed. Madrid, España: Editorial Catarata.

Santofimio, J.O. (1994). Acto administrativo. Procedimiento, eficacia y validez, $2^{\mathrm{a}}$ ed. Ciudad de México, México: Universidad Externado de Colombia y Universidad Nacional Autónoma de México.

Sorto, F.O. (2012). La compleja noción de solidaridad como valor y como derecho: la conducta de Brasil en relación a ciertos estados menos favorecidos. En M.G. Losano (Ed), Solidaridad y Derechos Humanos (97-120). Madrid, España: Editorial Dykinson S.L.

Urmson, J.O. (1985). Santos y héroes. En J. Feinberg (Ed). Conceptos morales (106-129). Ciudad de México, México: Fondo de Cultura Económica.

\section{Fuentes hemerográficas}

Álvarez, F.C. (2007). La naturaleza práctica de los actos supererogatorios. Civilizar ciencias sociales y humanas, 7 (13), 225-238.

Amuchastegui, J.G. (1991). Notas para la elaboración de un concepto de solidaridad como principio político. Sistema, 101, 126-134.

Carracedo, J.R. (2008). "El discurso sobre la desigualdad" de Rousseau como historia filosófica. Thémata. Revista de Filosofía, 40, 245-254.

De Lucas, J. (1996). La obligatoriedad de un servicio social y los deberes de solidaridad. Cuadernos de trabajo social Universidad Complutense, 9, 153-186.

Valdés, E. G. (1986). Los deberes positivos generales y su fundamentación. Cuadernos DOXA de Filosofía del Derecho, 3,17-33.

\section{Fuentes electrónicas}

De Benoist, A. (1971). Releer a Rousseau. Trad. José Antonio Hernández García. Francia: Asociación alaindebenoist.com. Recuperado de http://alaindebenoist.com/pdf/releer_a rousseau.pdf 
The concept of solidarity from the philosophical thought of the law

of jesús gonzález amuchastegui

De los Ríos Urruti, F. (1926). El sentido humanista del socialismo. España: Fundación Fernando De Los Ríos. Recuperado de http:// www.fernandodelosrios.org/images/obras/ E1\%20Sentido\%20Humanista\%20de1\%20 Socialismo.pdf

Mill, J.S. (1859). Sobre la libertad. Trad. Josefa Sainz Pulido, Pról. Antonio Rodríguez Huescar. Argentina: Ateísmo positivo. Recuperado de http://www.ateismopositivo. com.ar/Stuart\%20Mill\%20John\%20-\%20 Sobre\%20la\%20libertad.pdf
R.A.E. (2001). Solidario. Madrid: Real Academia de la Lengua. Recuperado de http:// lema.rae.es/drae/?val=solidario

Rousseau, J.J. (1999). Discurso sobre el origen de la desigualdad. España: elaleph. com. Recuperado de http://www.enxarxa.com/ biblioteca/ROUSSEAU\%20Discurso \%20 sobre $\% 201 a \% 20$ desigualdad.pdf 